\title{
Spatial health and life sciences business ecosystem: a case study of San Diego
}

\author{
Jukka Majava, Pekka Leviäkangas, Tuomo Kinnunen, Pekka Kess, Del Foit*, (2016) "Spatial health and \\ life sciences business ecosystem: a case study of San Diego", European Journal of Innovation \\ Management, Vol. 19, No. 1, pp. 26 - 46 \\ Industrial Engineering and Management Research Unit, University of Oulu, Oulu, Finland \\ *Rady School of Management, University of California San Diego, San Diego, California, USA
}

The final publication is available at: http://dx.doi.org/10.1108/EJIM-01-2015-0003

Purpose: Increasing competition in global markets requires many countries to seek new growth sectors. In addition, the nature of competition is changing. This paper applies the business ecosystem concept and studies San Diego as a spatial health and life sciences ecosystem. The aim is to identify issues that should be considered in design of innovation policies and regional industry development.

Design/methodology/approach: The research approach is built on a literature review of business ecosystems and spatial innovation. The empirical study is based on semistructured interviews, observations, and information gathering and verification during field research.

Findings: The results include a description of the ecosystem structure and dynamics. This paper demonstrates the bottom-up nature of San Diego's health and life sciences ecosystem without a dominant lead actor, and presents prerequisites for fostering spatial ecosystems.

Research limitations/implications: A single case may not be able to offer a generalized picture of this topic. However, the study raises several considerations for researchers and decision-makers involved in innovation policy design. Future work should extend the study and involve other spatial and substance contexts to compare findings and to pursue a more generic picture of innovation ecosystems and networks.

Originality/value: This paper demonstrates that applying the concept of business ecosystems to the spatial context provides new insights in terms of dynamic mechanisms and factors contributing to economic growth in a particular location. Understanding how to facilitate the creation of successful spatial ecosystems is in the focal point of innovation policies.

Keywords: business ecosystem, health and life sciences, innovation, San Diego, spatial context

Paper type: Case study 


\section{Introduction}

Structural changes of traditional industries, while facing increasing research and development (R\&D) based competition from developing countries such as China, Brazil, India, and Russia, force developed countries to search for new growth sectors to be competitive in global markets (Landabaso, 2014). The rapid convergence of technologies combined with increasing globalization poses a challenge for companies, decision-makers, and the entire spectrum of other stakeholders. Competition increasingly takes place between business ecosystems rather than between individual companies.

Business ecosystems tie different actors together through the flow of knowledge and shared value creation processes (Iansiti and Levien, 2004; Moore, 1993). The business ecosystem concept can offer insights into change dynamics and related strategic consequences, which is one of its main advantages over previous concepts like clusters and value chains (Makinen and Dedehayir, 2012; Porter, 2000). While clusters are often tied to a specific geographical location, the cluster concept has been criticized as being unable to explain the underlying factors that contribute to the success of certain locations (Kim, 2013). Clusters are also discussed in the broader context of regional innovation systems (Cooke, 2002). Yet, the innovation system policy approach that is popular in Europe is claimed to rely excessively on public interventions, which results in poor competiveness (Cooke, 2001). Despite the value of cluster and regional innovation system literature, our study aims to provide new insights in a spatial context by utilizing business ecosystem concept. Business ecosystems are considered to be private sector-led and they may span over regional boundaries; while some ecosystem actors are global, they also have local presence (Clarysse et al., 2014). Thus, the business ecosystem view is relevant and provides valuable insights in spatial contexts, where proximity enhances knowledge sharing and exchange (Carayannis and Campbell, 2009). Being part of dense knowledge network has been found important especially in life sciences (Whittington et al., 2009).

Many countries see health and life sciences as a source of economic growth and seek for novel solutions to relieve growing health care expenditures (Blank et al., 2013; Herzlinger, 2006). Rising costs, demographic changes, and the fact that health care can benefit from advances in life sciences drives cooperation between the different health and life sciences sectors (Blank et al., 2013). Information technology is another key innovation driver in health care (Omachonu and Einspruch, 2010). Health and life sciences can be seen as two partially nested concepts. The life sciences are "concerned with the study of living organisms, including biology, botany, zoology, microbiology, physiology, biochemistry, and related subjects" (Oxford Dictionaries, 2014). The health sciences, in turn, can be seen as a branch of life sciences including the areas of medicine and medical sciences, with several sub-disciplines that apply science to health. Health organizations serve many purposes, including prevention, diagnosis, treatment, education, research, and outreach (Omachonu and Einspruch, 2010). Thus, the health and life sciences ecosystem can be considered to include all public and private actors that are in the business of contributing to human health. The ecosystem includes various firms that offer products and services, universities, research institutions, and different intermediaries. Governmental involvement should also not be neglected, as proved by the vast political issues related to the Affordable Care Act in the USA (Zwelling and Kantarjian, 2014). 
Despite growing competition, the USA is still the global leader in life sciences and the country dominates, for example, the number of patent applications. The three leading life sciences areas in the USA include the Greater Boston area, the San Francisco Bay area, and San Diego (JLL, 2014). Appendix 1 presents information on international patent (PCT) applications; while the Greater Boston area and the San Francisco Bay area lead in total number of patent applications, San Diego has filed significantly more patent applications per inhabitant. The former two areas have received the most interest in academic literature. As an example, Kenney (2000) has discussed innovation and new firm formation in the San Francisco Bay area; the results highlight, for example, the importance of venture capitalists and law firms. However, there is an increasing interest in San Diego and its unique characteristics. Previous studies of San Diego include the works of Porter (2001), Walcott (2002), Jones (2005), Casper (2007), Global CONNECT (2010), Kim (2013), Casper (2014), Walshok and Shragge (2014), and Walshok and West (2014). The previous studies shed light on many important aspects of San Diego's innovation economy, including the roles of university, pioneer companies, and other institutions, and the importance of social networks, cultural aspects, and collaborative learning. For example, Casper (2014) highlights the importance of entrepreneurial and managerial networks in driving San Diego's success in the biotechnology sector.

To increase our understanding of what makes San Diego successful, the present study approaches the phenomenon as a spatial business ecosystem, including its structure and dynamic mechanisms. The aim of the study is to identify issues that should be considered in design of innovation policies and regional industry development. These issues are in the focal point of innovation policies. Innovation policies, be they local, national, or regional, are almost always spatially oriented in their measures. The target is to create local circumstances that create competitive advantages in global markets. Yet, the study by Clarysse et al. (2014) indicates a disconnect between development of research focused knowledge ecosystems and private sectorled business ecosystems. Policy efforts have primarily focused on the creation of knowledge ecosystems, with the assumption that this will automatically lead to the development of business ecosystems. However, this is not often the case. A holistic perspective on spatial ecosystems is needed to bridge this gap.

This paper describes the structure and dynamics of the health and life sciences business ecosystem in San Diego. The concepts used in this paper are briefly described as follows. Structure is defined as "the arrangement of and relations between the parts or elements of something complex" (Oxford Dictionaries, 2015a). In this study, the structure refers to the ecosystem actors, their roles, and relations. The term dynamics, in turn, has many contextdependent definitions. For example, dynamics can be defined as the forces or properties which stimulate development or change within a system (Oxford Dictionaries, 2015b).

This paper includes a literature review and an empirical part. Reviewed literature includes concepts of business ecosystems, innovation in spatial context, and previous studies of San Diego. The empirical study is based on semi-structured interviews with people who possess indepth knowledge about the ecosystem, including leaders and advisors in academic, research, business, and intermediary organizations, and entrepreneurs and investors. Observations and information gathering and verification during field research are also utilized. 


\section{Literature review}

\subsection{Business ecosystems and spatial innovation}

Moore (1993) introduced the term 'business ecosystem' in academic literature. Other significant contributions include Iansiti and Levien (2004), Santos and Eisenhardt (2005), Adner (2006), Teece (2007), and Adner and Kapoor (2010). In addition, empirical and conceptual studies have been conducted, including studies of mobile and digital business ecosystems (Basole, 2009; Corallo et al., 2007).

Business ecosystems develop through self-organization, emergence, and coevolution (Peltoniemi and Vuori, 2004). The business ecosystem life-cycle includes four stages: birth, expansion, leadership, and self-renewal or death (Moore, 1993). In business ecosystems, companies develop mutually beneficial relationships with customers, suppliers, and competitors (Iansiti and Levien, 2004). Coevolution occurs around a new innovation: organizations cooperate and compete to support new products, to satisfy customer needs, and to create succeeding innovations. Other actors adjust to the rules set by lead actors (keystones or platform leaders) that may change in the future. However, the community, including niche players and intermediaries, values the ecosystem leaders who enable members to move toward a shared future and benefits (Iansiti and Levien, 2004; Moore, 1993; Moore, 1996).

Ecosystem rules result from coevolution and interactions between the participants. The keystone company, and the level of control assumed by it, is a significant factor that affects the ecosystem internally. External factors affecting the ecosystem include changes in the social, economic, technological, and competitive environment (Makinen and Dedehayir, 2012). Furthermore, constraints are set by the competitive forces, regulators and legislation, standardsetting bodies, social norms, and business ethics (Teece, 2007).

Innovations are vital in business ecosystems. For innovations to occur, suitable environmental conditions are needed (Trott, 2012). According to Casper (2013), the innovativeness and success of certain geographical regions can be viewed from three different perspectives: universities as anchors of regional clusters, social networks as an enabling factor, and institutional frameworks. The role of universities in economic development has also been discussed by Geiger (2004). From a spatial viewpoint, necessary environmental conditions include adequate basic research, willing investors, talented people, and capital (Suh, 2010). Hwang and Horowitt (2012) emphasized talent diversity, trust across social barriers, motivations above short-term rationality, and social norms that promote rapid collaboration and experimentation. In their view, talent, ideas, and capital are the nutrients that move through the business ecosystem.

A triple helix type of collaboration between academia, industry, and government is claimed to accelerate innovations and the creation of new organizations and institutions, such as venture capitalists and incubators (Etkowitz and Leydesdorff, 1997; Mok, 2012). Therefore, many regions are trying to achieve an innovation environment that includes university spin-offs, initiatives for knowledge-based economic development, and boundary-spanning and partnerships between companies, government laboratories, and academic research groups (Etkowitz and Leydesdorff, 2000). The innovation support initiatives also include legislation changes, financial support, entrepreneurial development, and the establishment of new foundations, organizational forms, and programs (Etkowitz and Leydesdorff, 2000; Youtie and Shapira, 2008). For example, 
European policy initiatives aim to modernize the industrial base through the acceleration of innovation. This involves successful product and service innovations, the utilization of innovative production technologies and processes, and novel business models (European Commission, 2014a). Regional innovation is considered the key to creating growth; cities and regions are seen as key spatial units for knowledge transfer, innovation, and attracting investments and talent. Geographical proximity enhances knowledge acquisition, accumulation, and utilization. Regional cooperation involves many stakeholders: companies, research institutes, and various other organizations whose competences and knowledge continuously accumulate (European Commission, 2014b).

\subsection{Previous studies of San Diego}

San Diego's focus on research and development started in the 1960s and was supported by federal government investments. Research institutes provided critical mass of R\&D capacity in the mid1980 s and attracted international firms and venture investors. In addition, three pioneer startup companies, Linkabit (wireless), ISSCO (computer graphics), and Hybritech (biotechnology), played a key role (Jones, 2005; Kim, 2013; Walshok and Shragge, 2014). Due to reductions in the military sector, local leaders recognized the need to accelerate innovation, and an intermediary organization called CONNECT was established in the mid-1980s; the organization has been very successful in catalyzing local innovation (Walshok and Shragge, 2014). Currently, San Diego is especially strong in the sectors of wireless technology and life sciences (Walshok and West, 2014; JLL, 2014).

Over the years, many factors have been claimed as contributors to San Diego's success. Porter (2001) stressed the importance of educational and research institutions, the capability to attract federal and state research funding, the local talent pool, the role of local government in fostering a favorable business environment, formal and informal collaborations, and a location and climate that can attract external talent. According to Walcott (2002), key success factors include a worldclass research university, advocacy leadership, risk financing, an entrepreneurial culture, and appropriate real estate, together with an intensive network for information exchange. Jones (2005) and Casper (2007) emphasized the social networks and interactions and the role of Hybritech and the startups that were established by its former employees. San Diego has also been found to benefit from low barriers to entrepreneurs, experience in private-sector led initiatives, state investments in infrastructure, the capability for self-organization (instead of relying on government-led business development programs), the ability to gain federal research grants, highly interdisciplinary and entrepreneurial research institutions, strong personal networks and proactive engagement with resources and external decision makers, and the presence of pioneer companies such as Hybritech (Global CONNECT, 2010).

Hwang and Horowitt (2012) pointed out that San Diego's growth has been catalyzed by enterprise-friendly policy changes, transparent laws (for real estate, intellectual property, agreements, and corporations), low enough taxes and cost of setting up a new corporation, a network of people with experience in science, technology, business and business-related services, 
and the ability to attract global talent. Kim (2013), in turn, stressed the importance of learning and stated that, "to a large extent, the emergence of the San Diego biotechnology community was a process of creating and circulating local knowledge and practices." Walshok and Shragge (2014) argued that San Diego's success is based on five critical factors. These include natural advantage of place, values of early settlers, organizing communities for economic promise, the resources and talents the community cultivates, and how citizens define and promote their place. Furthermore, San Diego's civic culture is characterized by risk-orientation, entrepreneurial talent, integrative civic platforms, multiple gateways to develop ideas and opportunities, and a culture of reinvestment. In addition, Walshok and West (2014) stressed the university's role in developing talent for local companies.

\section{Method}

This research is based on the case study method (Yin, 2009). The empirical data for the case was acquired through interviewing key informants with in-depth knowledge on San Diego's health and life sciences ecosystem. In addition to interviews, secondary data sources were utilized. These secondary sources included observations and information gathering, and verification by participating in local events and following local media during a six-month period of field research. The research approach is built on a literature review, against which San Diego's case is reflected. The review deals with business ecosystems, innovation in spatial contexts, and previous studies of San Diego.

The twenty informants who were interviewed during the study included academic and business leaders, advisors, entrepreneurs, and investors. Five interviewees represented a university and another five represented different businesses. Three of the interviewees were from trade organizations, three were from incubator and accelerator organizations; two interviewees represented research institutes, and two were investors. It should also be emphasized that many of the interviewees had multiple roles and were involved in more than one organization. For instance, one of the research institute representatives had also founded two companies.

A semi-structured interview process was used to gain insights into the case and the interviewees' thoughts regarding selected topics. An average interview lasted roughly one hour, and interviews were recorded and transcribed for analysis. Each interview started with generic questions about the informants' background and the overall importance of ecosystems in today's business. Next, questions specifically addressed San Diego's health and life sciences business ecosystem, which was the main focus. These questions included details about the actors in the ecosystem and their roles, the factors that enhance growth of the ecosystem, and the evolution of the ecosystem.

After the first interviews, a list of ecosystem actors was created and utilized during the interview process. The data analysis followed guidelines by Eisenhardt (1989). The analysis was conducted using a qualitative approach, i.e. reading the interviews several times, each time going deeper into the data to find connections, patterns, and comparisons. Emerging patterns were structured into more generic categories that helped formulate the key concepts and issues. 


\section{San Diego's health and life sciences ecosystem}

\subsection{Ecosystem structure}

San Diego's health and life sciences ecosystem could be studied as separate, smaller entities divided based on different science areas, technological platforms, or theoretically even as entities where different health care providers are leaders of their own ecosystems. However, for this study, the unit of analysis is a common, spatial, business ecosystem. Figure 1 describes the ecosystem actors that were identified based on the interviews.

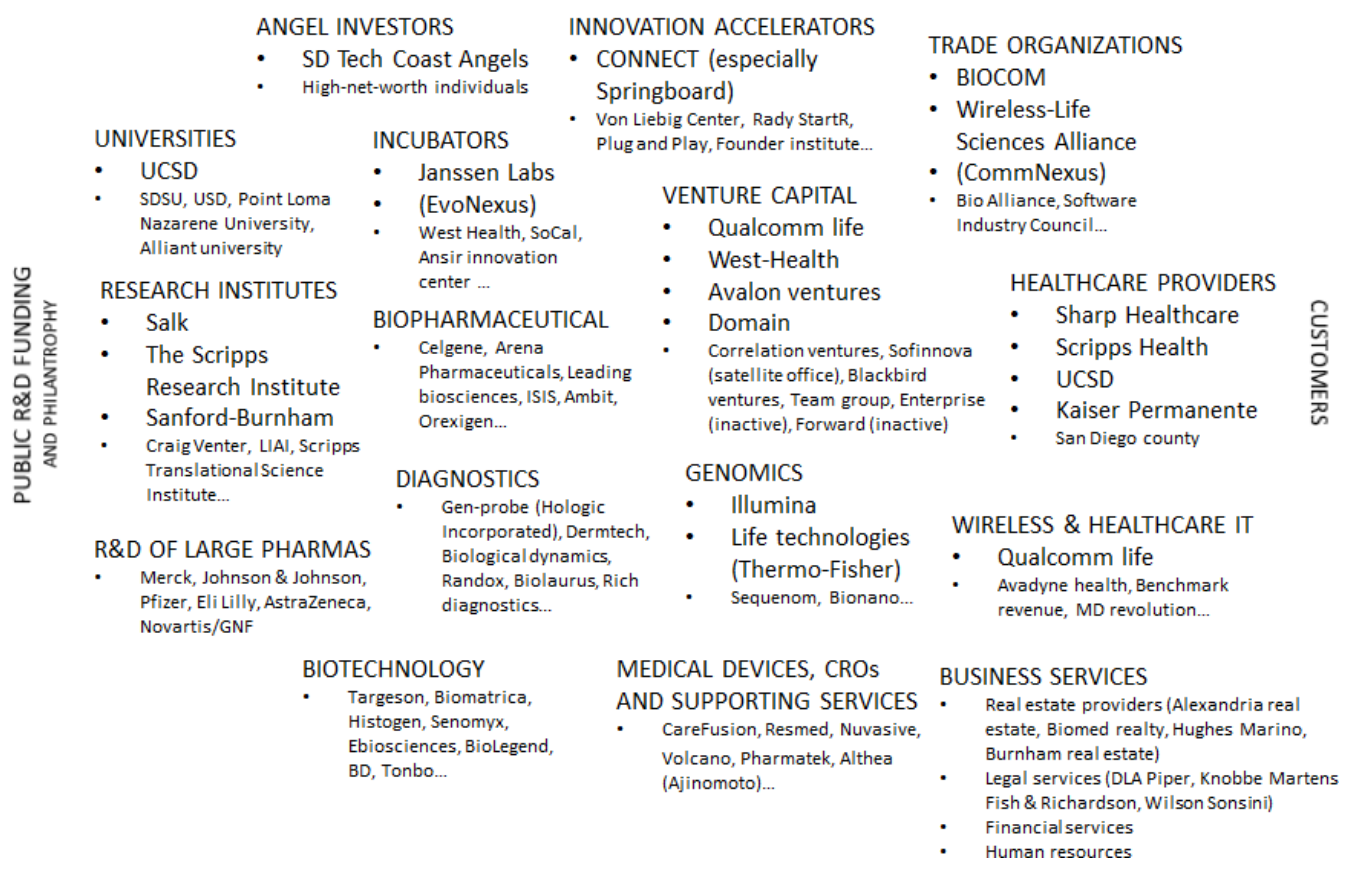

Figure 1. Actors in San Diego's health and life sciences ecosystem.

At the time of the study, San Diego's health and life sciences ecosystem included hundreds of companies and other organizations. Thus, only some of them were included to illustrate typical companies in each category. The ecosystem actors that were found to be especially important are highlighted in large font. Indicators illustrating the size of their operations are presented in Appendix 2. Analysis of the indicators shows that organization size does not equal importance; for example, one of the key actors, Wireless-Life Science Alliance, has only five employees.

\subsubsection{Universities and research institutes}

The interview data analysis identified the University of California San Diego (UCSD) and the other most established research institutes, including The Salk Institute, The Scripps Research Institute, and Sanford-Burnham Medical Research Institute as key actors in the ecosystem. These organizations are essential in acquiring research funding, creating new technologies and ideas to be commercialized, licensing the technologies, and training new talent. However, it should be 
noted that dozens of other research institutes also exist in the San Diego region. In addition to the most established organizations, J. Craig Venter Institute (genomics), La Jolla Institute of Allergy and Immunology, and Scripps Translational Science Institute (digital health) can also be considered very important. UCSD was identified as the most important actor among universities, followed by San Diego State University (SDSU). The University of San Diego (USD), Point Loma Nazarene University, and Alliant University support the ecosystem mainly by providing training.

\subsubsection{Accelerators and incubators}

San Diego's business ecosystem involves dozens of accelerator and incubator type programs and organizations. The accelerators provide a structured kind of mentoring and coaching, opportunities for networking, and matching companies with early stage funding, whereas incubators typically support startups with space, resources, and mentoring. (For further discussion on the differences between accelerators and incubators, see Miller and Bound 2011). Among the accelerators, the role of CONNECT Springboard was found to be especially critical based on interview data. However, some other prominent accelerators also exist, such as UCSD's Von Liebig Center and Rady School of Management's StartR. Among incubators, Janssen Labs was identified as the most important, with approximately 35 startups on its premises. Other prominent incubators in this ecosystem include EvoNexus, West Health, SoCal EED, and Ansir Innovation Center. While EvoNexus has traditionally focused on technology companies, many of its current companies develop connected health applications, which makes EvoNexus important in the health and life sciences ecosystem.

\subsubsection{Angel investors and venture capitalists}

Angel investors include organized angel networks, high-net-worth individuals, and "friends and family" supporting a starting entrepreneur. San Diego has a local chapter of Tech Coast Angels, which is the largest organized angel network in USA. In spite of relatively small investments, San Diego Tech Coast Angels was found to be a key actor in the ecosystem, as the angels play an important role in advising startups and helping to refine their business plans.

Venture capitalists (VCs) typically provide larger investments in later stages to support innovation and company growth. Qualcomm Life and West Health, both having 100 million dollar funds, are among the key VCs in the ecosystem. Other active VC firms in San Diego include Avalon Ventures, Domain, and Correlation Ventures. Based on the interview analysis, operations of other VCs are quite small and some of them are no longer active. Due to insufficient local venture capital, connections to VCs in the San Francisco Bay area were found to be very important.

\subsubsection{Companies}

Many large pharmaceutical companies, including Merck, Johnson \& Johnson, Pfizer, Eli Lilly, AstraZeneca, and Novartis are located in San Diego. Some of the aforementioned have $R \& D$ activities, whereas others use scouts to spot new innovations. Based on the interviews, pharmaceutical companies are important for the ecosystem, as their presence increases partnering and funding opportunities. 
In addition to these pharmaceutical companies, the ecosystem contains hundreds of other health and life sciences companies, including biotechnology, biopharmaceuticals, diagnostics, genomics, medical devices, contract research organizations (CROs), supporting services, and wireless health care and information technology (IT) providers. The interview analysis showed that these companies offer a talent pool for new companies and contribute to the continuous success of the ecosystem through new innovations and providing mentoring for new entrepreneurs in organizations like CONNECT. Despite the success of many San Diego based companies, most informants saw only Illumina and Life Technologies (acquired by ThermoFisher in 2014) as key actors in the ecosystem. Other important companies were found to be Qualcomm Life, Carefusion, Resmed, Gen-probe (acquired by Hologic), Celgene, Nuvasive, Arena, and Volcano.

\subsubsection{Trade organizations}

Biocom and Wireless-Life Sciences Alliance were identified as the ecosystem's key trade organizations. CommNexus (formerly San Diego Telecom Council) was also found important due to growth in connected health applications. Trade organizations provide resources and advocacy for their members, which typically include more established companies. Trade organizations also provide local and global networking opportunities. While Springboard accelerator program was found to be the core activity of the CONNECT organization, CONNECT can also be described as a trade organization due to the advocacy of its Washington, D.C. office. The roles and tasks of CONNECT and Biocom overlap to some extent in the ecosystem.

\subsubsection{Health care providers}

Health care providers are the target market for health and life sciences companies and they provide a channel to end-customers (i.e. consumers). The health care providers were also identified as important partners in clinical trials. Issues in the US health care system were also brought up in the study; health care involves multiple systems without central leadership and interoperability does not exist, which makes the system very expensive. The most prominent health care providers in San Diego were identified as Sharp Healthcare, Scripps Health, UCSD Health System, and Kaiser Permanente. The share of public health care in San Diego was also found to be large. Interestingly, little collaboration was found between health care providers and other actors. Naturally, this depends on the organization's focus area. For example, one interviewee stated that "there is a 10 year gap between physicians and drug development." However, the interview analysis also revealed a need for more collaboration and clinical trials. Hospital investments, such as the UC San Diego Jacobs Medical Center, also provide opportunities to strengthen the ecosystem.

\subsubsection{Governmental actors}

Local, state, and federal governments provide the ecosystem with the infrastructure, rules (including legislation, regulation, and taxes), and policies that guide research funding. Based on the interview analysis, state and federal governments should fund basic research, but not interfere in the ecosystem with too many regulations and high taxation. Local government was considered currently weak, although the city of San Diego's role was important in providing very appealing 
land for UCSD, research institutes, and companies focusing on light industries. The California state government's three billion dollar investment in stem cell research can also be considered very important for the ecosystem. However, the state's high taxes and regulations combined with incentives offered by other states lure companies from San Diego, especially to Texas. The federal government was recognized as playing a big role, especially through National Institute of Health (NIH) and National Science Foundation (NSF) grants. In addition to research funding, $\mathrm{NIH}$ supports innovation and technology transfer through Small Business Innovation Research (SBIR) and Small Business Technology Transfer (STTR). Besides public funding, donations by local philanthropists, such as Sanford and Jacobs, support the ecosystem.

\subsubsection{Business service providers}

The interview analysis also identified business service providers (legal, financial, real estate, human resources) as ecosystem actors. While many of the services are industry independent, specialized companies also exist. Specialized providers include legal companies such as DLA Piper, Knobbe Martens, Fish \& Richardson, Wilson and Sosini. Specialized real estate providers include Alexandria Real Estate and BioMed Realty. Besides the value of their core services, many business service directors are involved in boards of different intermediary organizations and their contact networks help support the ecosystem.

The roles of different ecosystem actors are summarized in Table 1 below.

Table 1. Ecosystem actors and their roles.

\begin{tabular}{|l|l|}
\hline Actor & Contribution \\
\hline $\begin{array}{l}\text { Universities and research } \\
\text { institutes }\end{array}$ & $\begin{array}{l}\text { Acquire research funding, create new technologies and ideas to be } \\
\text { commercialized, train new talent, license technologies }\end{array}$ \\
\hline Accelerators & $\begin{array}{l}\text { Structured mentoring and coaching, networking, match companies with } \\
\text { early stage funding opportunities }\end{array}$ \\
\hline Incubators & Space, resources, and mentoring for startups \\
\hline Angel investors & Seed investments and provide advice for startups \\
\hline Venture capitalists & Invest to support innovation and company growth \\
\hline $\begin{array}{l}\text { Large pharmaceutical } \\
\text { companies }\end{array}$ & Potential partners and investors \\
\hline $\begin{array}{l}\text { Other health and life } \\
\text { sciences companies }\end{array}$ & Talent pool, contribute to the continuous success of the ecosystem \\
\hline Trade organizations & $\begin{array}{l}\text { Advocacy and resources for member companies, local and global } \\
\text { networking }\end{array}$ \\
\hline Health care providers & Target market, channel to end-customers, partner in clinical trials \\
\hline $\begin{array}{l}\text { Local, state, and federal } \\
\text { governments }\end{array}$ & $\begin{array}{l}\text { Infrastructure, rules (legislation, regulations, taxes), policies, research } \\
\text { funding }\end{array}$ \\
\hline Business services & $\begin{array}{l}\text { Legal, financial, real estate, and human resources, contact networks } \\
\text { that support the ecosystem }\end{array}$ \\
\hline
\end{tabular}

\subsubsection{Distinguishing qualities}

"The ecosystem here on a global basis is one of the top 5. It's different than the others in that we don't have a Harvard here, we don't have Silicon Valley next to us, and so it's a bit of an outpost, 
which makes it in some ways self-sustaining. What you see then is a lot of startups here in San Diego, probably more per capita than any of the other biotech hubs, and when they are successful and they sell their firms, because it's pretty good weather, people like to stick around here. The capabilities stay resident, feed back into new startups and the whole thing starts over again. So I would say in many ways we're more innovative and more entrepreneurial, we're not as big though." - CEO of a life sciences company

San Diego's health and life sciences ecosystem has a bottom-up nature, and is very diverse and self-organized. A single leader for the ecosystem was not identified, although some interviews indicated leaders of CONNECT and Biocom and a group of individuals to provide the leadership. In this sense, San Diego's health and life sciences ecosystem was found to differ considerably from the wireless technology ecosystem, which is clearly led by one company, Qualcomm. The health and life sciences ecosystem lacks a big anchor company, although Hybritech used to have that role in the 1980s and Illumina's influence has recently increased. In addition, Qualcomm Life and Janssen Labs may become more influential in the future.

A common platform for the ecosystem was not identified, although the university and research institutes can be considered the platform for new discoveries. In addition, different intermediaries and venues, including CONNECT, Biocom, MIT Enterprise Forum, San Diego Venture Group, CommNexus, EvoNexus, and Janssen Laboratories, can be seen as platforms for networking and funding access. Startup companies and the rise of genomics can also be considered important innovation platforms. The interviews indicated that the following rules exist in the ecosystem: laws, regulation, business rules, and social rules.

The scientific base in the San Diego's health and life sciences ecosystem is very strong and includes both diversity and density. Traditionally strong research areas include cancer, neurosciences, and diagnostics. However, genomics and next generation sequencing were identified as increasingly important. The health and life sciences ecosystem is also converging with wireless, sports, and lifestyle sectors.

Based on the interviews, proximity is a key differentiator of the San Diego ecosystem compared to the San Francisco Bay and Greater Boston areas. One CEO stated "if you look at the other big areas like San Francisco and Boston... you have to physically go a reasonable distance to meet with some other people. Here in San Diego, at least in my particular location, I can walk to a meeting with five of the major research institutes."

Interviews also proved the business and academic culture of San Diego as very entrepreneurial. The founders of UCSD understood the importance of collaboration with the industry. In addition, the first scientists recruited by UCSD were "risk-takers," willing to leave well-established universities to pursue their interests at a university without scientific reputation. The entrepreneurial culture became stronger through early successes, such as a pioneer company Hybritech, which proved that science and business can complement each other. These successes continuously feed the ecosystem, and a large number of intermediary organizations also illustrate entrepreneurial culture; if the actors see a gap in the ecosystem, they tend to fill it.

The culture of collaboration is also important in this ecosystem based on interview analysis. San Diego is a relatively small community, where people know each other and try to build good relationships. In some cases, people help new entrepreneurs by providing office space or 
laboratory services for free and even help their competitors in less critical areas. However, it may be difficult to claim that the collaboration in San Diego is unique compared to other locations. International collaboration was also identified as vital for the ecosystem. Many researchers come to San Diego from abroad, and global pharmaceutical companies are present due to the ecosystem's strengths in research, development, early prototyping, and new opportunities that are provided by the convergence of different sectors. Due to its location, connections with Latin America and Asia were found to be stronger than connections with Europe.

\subsection{Ecosystem dynamics}

Innovation can be seen as the main source of dynamics in the ecosystem. A typical innovation cycle in the San Diego's health and life sciences ecosystem begins with a technology based idea that often originates from government funded basic research at university or research institutes. The commercialization of the invention requires early stage work, such as protection of intellectual property. Actors supporting the early stage include, for example, UCSD von Liebig Center and Rady StartR accelerators. Licensing the invention to an existing company or a new startup involves technology transfer by an organization such as UCSD Technology Transfer Office (TTO).

The startup phase can involve accelerators and incubators, such as CONNECT's Springboard program and Janssen Labs. Seed funding is typically acquired from angel investors (e.g. San Diego Tech Coast Angels). Successful companies acquire more funding from venture capitalists and recruit new employees from local or external talent pools. More established companies typically join trade organizations, such as Biocom or Wireless-Life Sciences Alliance. If the success continues, an initial public offering (IPO), a merger, or acquisition by another company may take place. Figure 2 presents a typical innovation cycle in San Diego's health and life sciences business ecosystem.

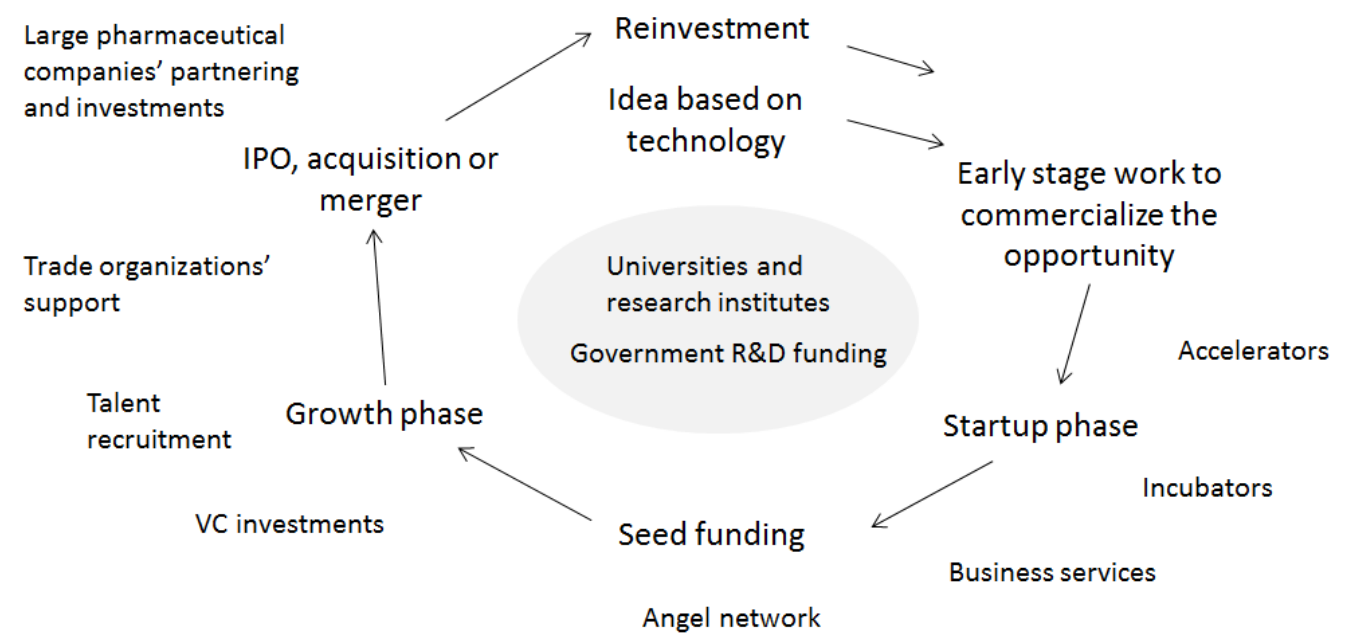

Figure 2. Typical innovation cycle in the health and life sciences ecosystem based on San Diego case study. 
The innovation cycle presented above is a generic conceptualization that may be typical for life sciences sector. However, most inventions will not end up in the market. Any stage of the cycle can be critical and many factors may decide whether an innovation becomes a success or not. Despite the failures, the constant innovation enables the creation of a local resource pool that, for example, lowers the recruitment costs in new ventures. In addition to failures, a merger or an acquisition can occur at any stage; San Diego based companies are often bought before they grow large.

Based on interview analysis, the ecosystem is considered good for startups, but growing midsized companies is difficult. Acquired companies may relocate their operations, as in the case of Amylin Pharmaceuticals, which was bought by Bristol-Myers Squibb. However, employees often prefer to stay in San Diego and start their own companies. People also tend to reinvest in the local ecosystem. In the case of success, reinvestments can be financial, whereas failures result in continuous learning that makes the ecosystem stronger. Reinvestment often involves time spent mentoring and coaching new entrepreneurs.

Various factors contribute to the growth of San Diego's ecosystem. Based on the interviews, capital was found to be the main factor enabling growth. Sources of capital within the ecosystem include angel investments, venture capital, capital from acquisitions, IPOs, and successes and exits. However, insufficient availability of local venture capital was identified to inhibit growth, despite good access to venture capital in the San Francisco Bay area. Macroeconomic factors also affect capital availability; some interviewees pointed out that currently, "money is tight and riskaverse."

Universities and research institutes that provide new ideas and technology were recognized as the second most important factor contributing to growth; this factor was highlighted by almost half of the interviewees. Furthermore, it should be emphasized that universities and research institutes are critical in acquiring NIH and NSF grants, which were also found to be major growth enablers; San Diego based organizations receive two billion dollars in grant money annually. Philanthropic support of research cannot be neglected either.

As discussed earlier, a single leader in the San Diego's health and life sciences ecosystem was not identified. However, many interviews indicated that successful local companies, such as Illumina in genomics, drive ecosystem growth. In addition, the presence of international pharmaceutical companies is also considered important. Some interviewees stated that San Diego is a place "that makes people stay" for instance due to a good quality of life; the ability to retain talent contributes to ecosystem growth.

Entrepreneurs and business people were also identified as enablers of growth in the ecosystem, and the establishment of Rady School of Management provides new management talent locally. Other factors identified to contribute to growth include new opportunities and business areas, incubators and other intermediary organizations with networking opportunities, the overall business climate, proximity that leads to collaboration, ideation and commercialization, a global interest towards San Diego, and local leaders.

Factors that inhibit the growth of this ecosystem were also analyzed. Besides insufficient local venture capital, the main inhibitors were found to include political and legal issues, including patent law, taxes, regulations, FDA approvals, and uncertainties related to them. In addition, competition between states, such as tax incentives provided by Texas, draws companies 
away from San Diego. Lack of entrepreneurial talent and certain technical talents (software experts, chemists, and medical technicians) also inhibit growth to some extent. Insufficient research funding and uncertainties about its future, the cost of living, and a small airport with insufficient domestic and international connections were also identified as issues. Other growth inhibitors that were identified included: university technology transfer processes, uncertainty and irrationality regarding how health care is financed and paid, lack of large companies' headquarters, image issues of being still considered as "a small military town," insufficient cooperation between organizations, a lack of pharmaceutical manufacturing (and thus a lack of chemists and chemical engineers), and the high cost of building large businesses due to the lack of real estate and expensive land. Interestingly, mindset issues were also identified. For example, one investor stated that crazy ideas are often criticized in San Diego, whereas the approach in Stanford is, "that's a cool idea, let's figure out how it could work."

\subsection{Ecosystem's future prospects}

San Diego's health and life sciences ecosystem has a lot of strengths in different areas. The ecosystem is growing and continuous learning occurs among actors. The data analysis indicated that the main trend is a convergence between health and life sciences and the technology sector, especially wireless. This development, also known as connected health, involves many areas, such as mobile health, digital health, various applications, sensor use, big data, and personalized medicine. Examples of the convergence include the growing influence of Qualcomm Life and the UCSD School of Medicine's collaboration with the School of Engineering. Another important trend identified by interviewees is the rise of genomics and sequencing. The roles of Illumina, Life Technologies, and Craig Venter are important in driving the future of genomics in this ecosystem. The stem cell field can be considered almost as important as genomics.

Based on the interviews, the need to improve health care efficiency and the fact that hospitals are becoming more active are expected to drive new innovations in this ecosystem. New opportunities can also be found in bioprinting, bioengineering, brain research, neural sciences, cancer, and stroke prevention. The interviewees also expected more clinical research to take place in this ecosystem. The convergence of computing and biology, and opportunities in complementing sectors like sports, lifestyle, food, and beverages were also identified to be growing trends.

From a resources point of view, the interviewees saw that the growth in initial public offerings (IPOs), which started in 2013, is likely to continue. This would bring more capital into the ecosystem. New forms of funding, including syndication and crowdfunding, are also under development. However, federal research funding is not expected to grow according to the interviewees. This requires research institutes to change; they must focus more on commercialization and create more public-private partnerships. Pharmaceutical companies may also become more interested in early stage opportunities.

Despite its evolution, San Diego is unlikely to become a first-tier city in the global economy. As one interviewee pointed out, San Diego "is somewhat isolated, close to the mega city of Los Angeles, and capital and IT talent is located mainly in the San Francisco Bay area." Due to increasing global competition, local companies should be active in acquiring more capital and 
becoming more international. One interviewee stressed that the competition for postdocs is increasing, and places such as Germany, Shanghai, and Singapore provide more money for talented researchers. The high cost of doing business in California, water issues, and regulatory barriers at the federal level are also issues that may have significant effects on the ecosystem. The local government's unwillingness to develop San Diego at a greater rate and differences in economic activities and interests between the city center and the area with a high concentration of health and life sciences were also brought up as issues that may negatively affect the ecosystem evolution.

\section{Discussion and conclusions}

Cities and regions can be viewed as spatial units for innovation. This study addressed health and life sciences in San Diego as a spatial business ecosystem. The ecosystem structure and dynamic mechanisms were identified. Clearly, San Diego's success in health and life sciences is based on various factors and it would be difficult to replicate in other spatial locations. However, our study raises several points that should be considered by researchers and decision-makers who contribute to the design of innovation policies, since policy efforts have typically focused on fostering knowledge ecosystems with an assumption that development of business ecosystem follows. However, previous research indicates this assumption to be questionable (Clarysse $e t$ al., 2014). For example, a balance should exist between genuine risk financing and public support.

Based on our study, the availability of different forms of capital is a prerequisite for facilitating the creation of a successful spatial business ecosystem. Capital requirements include venture capital, an angel network, reliable funding sources for research and startups, and access to capital that is close and has long-term patience. Capital needs are not solely financial, however. For example, angel investors often provide valuable mentoring for startups. In addition, venture capital can be located outside the spatial ecosystem; in San Diego's case, access to venture capital in the San Francisco Bay area was recognized as one of the growth enablers. Thus, ensuring access to capital is a necessity.

Cultural issues should not be neglected either. The interviews indicated the importance of a culture that is open to entrepreneurship and risk-taking, and is willing to accept failure. These findings are also supported by earlier studies (Walcott, 2002; Walshok and Shragge, 2014). The aforementioned culture must be supported by local leaders. Furthermore, local conditions must be attractive to people and encourage them to stay in the ecosystem. Past literature provides similar conclusions; the capability to attract external talent has been identified as one of San Diego's success factors (Hwang and Horowitt, 2012; Porter, 2001). Local decision-makers should ensure that their location offers a good quality of life.

Success in health and life sciences requires infrastructure for research and making the most of available talent. Previous studies (Global CONNECT, 2010; Porter, 2001; Walcott, 2002; Walshok and West, 2014) stressed that, in addition to educational institutions, San Diego has benefitted greatly from research institutes that are capable of acquiring research funding. The present study also indicates that a strong well-funded university and research institutes are vital. 
Therefore, sufficient public investments in research and education are absolutely critical for a successful ecosystem.

Platforms for formal and informal cooperation, collaborative learning, social networks, and the role of pioneer companies have also been highlighted in previous studies (Casper, 2007; Jones, 2005; Kim, 2013; Porter, 2001; Walcott, 2002; Walshok and Shragge, 2014). Based on the results of this study, a successful spatial ecosystem includes networking and collaboration between companies and people, the proximity of key ecosystem actors, human capital (including scientists, entrepreneurs, and serial entrepreneurs), and the presence of companies that provide downstream opportunities. Proximity of actors was found especially important in San Diego case; local decision-makers can and should affect the element of proximity with land use and urban planning decisions.

A healthy spatial ecosystem needs committed leadership and people who work together to develop the region. As one interviewee pointed out, "Everybody has to be tending to the care of the ecosystem at all times to make it work, and you have to trust, you have to believe, there's a little bit of faith involved in making it happen." The interview analysis indicated that celebrating and promoting business and research successes is important, because this helps attract funding and new entrepreneurs to the ecosystem. Support systems for startups, including networks of mentors and advisors and incubators are also important and their availability should be ensured.

The ecosystem in San Diego allows people the freedom to pursue their interests, and the ecosystem is not governed by top-down planning. The bottom-up nature of the ecosystem is a key finding in our study, and it indicates that top-down approach may not be successful in fostering ecosystems. For example, demand-driven innovation, meaning in essence the public procurements that seek novel solutions might not work effectively in creating sustainable innovation. However, this does not mean that public actors do not have any role in the ecosystem. Previous studies suggested that the local government has had a role in creating a favorable business environment in San Diego, and the region has benefitted from public investments (Global CONNECT, 2010; Porter, 2001). This study also indicates that public actors can contribute to ecosystem growth via infrastructure, legislation, regulations, taxes, policies, and the allocation of research funding. For example, financial regulations should not prevent angel and $\mathrm{VC}$ investments. As many attempts and investments will also fail, the regulatory management of these failures should not pose an overwhelming threat to potential investors and entrepreneurs. For example, regulations on bankruptcy and investor exit must not be excessively discouraging.

The success factors for creating a spatial ecosystem also depend on local conditions. However, research intensive sectors require unique focus areas of expertise. Critical mass in selected research areas, ideas, diversity, and a rapid technology transfer from universities and research institutes should be ensured. In health and life sciences, the quality and innovation of local health care providers, and increasing their collaboration with other ecosystem actors, could enable success. Thus, options to help foster this collaboration should be considered.

This paper shows that applying the concept of business ecosystems in a spatial context provides new insights in terms of dynamic mechanisms and factors contributing to economic growth in a particular location. This study also demonstrates the bottom-up nature of San Diego's health and life sciences ecosystem, which is somewhat in conflict with the traditional view of business ecosystems with lead actors (Moore, 1993). Recommended future research includes 
other spatial and substance contexts to compare and validate these findings and to pursue a more generic picture of innovation ecosystems and networks. In addition, the role of trust and the CONNECT organization in San Diego's ecosystem deserve additional attention.

\section{References}

Adner, R. (2006), "Match your innovation strategy to your innovation ecosystem", Harvard Business Review, Vol. 84, No.4, pp. 98-107.

Adner, R. and Kapoor, R. (2010), "Value creation in innovation ecosystems: how the structure of technological interdependence affects firm performance in new technology generation", Strategic Management Journal, Vol. 31, No. 3, pp. 306-333.

Basole, R.C. (2009), "Visualization of interfirm relations in a converging mobile ecosystem", Journal of Information Technology, Vol. 24, No. 2, pp. 144-159.

Blank, W., Frank, P., and Karopka, T. (2013), "Health and life sciences as drivers for regional development and prosperity in the Baltic Sea Region", Journal of East-West Business, Vol. 19, No. 1-2, pp. 122137.

Carayannis, E. G. and Campbell, D. F. (2009), “'Mode 3' and 'Quadruple Helix': toward a 21st century fractal innovation ecosystem”, International Journal of Technology Management, Vol. 46, No. 3, pp. 201234.

Casper, S. (2007), "How do technology clusters emerge and become sustainable?: Social network formation and inter-firm mobility within the San Diego biotechnology cluster", Research Policy, Vol 36, No 4, pp. 438-455.

Casper, S. (2013), "New-technology clusters and public policy: three perspectives", Social Science Information, Vol. 52, No. 4, pp. 628-652.

Casper, S. (2014), "The University of California and the evolution of the biotechnology industry in San Diego and the San Francisco Bay area", in Kenney, M. and Mowery, D. (Eds.), Public Universities and Regional Growth: Insights from the University of California, Stanford University Press, pp. 6696.

Clarysse, B., Wright, M., Bruneel, J., and Mahajan, A. (2014), "Creating value in ecosystems: Crossing the chasm between knowledge and business ecosystems", Research Policy, Vol. 43, No. 7, pp. 1164-1176.

Cooke, P. (2001), "Regional innovation systems, clusters, and the knowledge economy", Industrial and corporate change, Vol. 10, No. 4, pp. 945-974.

Cooke, P. (2002), "Regional innovation systems: general findings and some new evidence from biotechnology clusters", The Journal of Technology Transfer, Vol. 27, No. 1, pp. 133-145.

Corallo, A. (2007), "The business ecosystem as a multiple dynamic network", in Corallo, A., Passiante, G. and Prencipe, A. (Eds.), The digital business ecosystem, Edward Elgar Publishing, Cheltenham, UK, pp. 11-32.

Eisenhardt, K.M. (1989), "Building theories from case study research", Academy of Management Review, Vol. 14, No. 4, pp. 532-550.

Encyclopedia Britannica. (2014), "Evolution", available at: http://www.britannica.com/bps/dictionary?query=evolution (accessed 11 April 2014).

Etzkowitz, H. and Leydesdorff, L. (1997), Universities and the Global Knowledge Economy: A Triple Helix of University-Industry-Government Relations, Cassell Academic, London. 
Etzkowitz, H. and Leydesdorff, L. (2000), "The dynamics of innovation: from national systems and "mode 2" to a Triple Helix of university-industry-government relations", Research Policy, Vol. 29, No. 2, pp. $109-123$.

European Commission. (2014a), "Innovation policy", available at: http://ec.europa.eu/enterprise/policies/innovation/policy/index_en.htm (accessed 19 December 2014).

European Commission. (2014b), "Regional innovation", available at: http://ec.europa.eu/enterprise/policies/innovation/policy/regional-innovation/index_en.htm (accessed 19 December 2014).

Geiger, R. L. (2004). Knowledge and Money: Research Universities and the Paradox of the Marketplace, Stanford University Press, Stanford, California.

Global CONNECT. (2010), "Biotechnology cluster project San Diego Analysis", United States Studies Centre, University of Sydney, Australia.

Herzlinger, R. E. (2006), "Why innovation in health care is so hard", Harvard Business Review, Vol. 84, No 5, pp. 58-66.

Hwang, V.W. and Horowitt, G. (2012), The Rainforest: The Secret to Building the Next Silicon Valley, Regenwald, Los Altos Hills, California, USA.

Iansiti, M. and Levien, R. (2004), "Strategy as ecology", Harvard Business Review, Vol. 82, No. 3, pp. 68$78+126$.

JLL. (2014), Life Sciences Cluster Report.

Jones, M. P. (2005), Biotech's perfect climate: The hybritech story, Doctoral dissertation, University of California, San Diego.

Kenney, M. (Ed.). (2000). Understanding Silicon Valley: The Anatomy of an Entrepreneurial Region, Stanford University Press, Stanford, California.

Kim, S. T. (2013), "Regional advantage of cluster development: a case study of the San Diego biotechnology cluster", European Planning Studies, (ahead-of-print), pp. 1-24.

Landabaso, M. (2014), "Guest editorial on research and innovation strategies for smart specialisation in Europe: theory and practice of new innovation policy approaches", European Journal of Innovation Management, Vol. 17, No. 4, pp. 378 - 389.

Makinen, S. J. and Dedehayir, O. (2012), "Business ecosystem evolution and strategic considerations: A literature review", Engineering, Technology and Innovation (ICE), 18th International ICE Conference in Munich, Germany, 18-20 June 2012, pp. 1-10.

Miller, P. and Bound, K. (2011), "The Startup Factories: The rise of accelerator programmes to support new technology ventures", NESTA.

Mok, K.H. (2012), "The quest for innovation and entrepreneurship: the changing role of university in East Asia", Globalisation, Societies and Education, Vol. 10, No. 3, pp. 317-335.

Moore, J.F. (1993), "Predators and prey: a new ecology of competition", Harvard Business Review, Vol. 71, No. 3, pp. 75-86.

Moore, J.F. (1996), The Death of Competition: Leadership \& Strategy in the Age of Business Ecosystems, HarperBusiness, New York.

OECD. (2014), "Innovation available at: http://stats.oecd.org/Index.aspx?DataSetCode=REG_INNO_TL2 (accessed 27 October 2014).

Omachonu, V. K. and Einspruch, N. G. (2010), "Innovation in healthcare delivery systems: a conceptual framework", Innovation Journal, Vol. 15, No. 1, pp. 2-20. 
Oxford Dictionaries. (2014), "Life sciences", available at: http://www.oxforddictionaries.com/definition/english/life-sciences?q=life+sciences (accessed 31 October 2014).

Oxford Dictionaries. (2015a), "Structure", available at: http://www.oxforddictionaries.com/definition/english/structure?q=Structure (accessed 10 April 2015).

Oxford Dictionaries. (2015b), "Dynamics", available at: http://www.oxforddictionaries.com/definition/english/dynamics?q=dynamics (accessed 10 April 2015).

Peltoniemi, M. and Vuori, E. (2004), "Business ecosystem as the new approach to complex adaptive business environments", Proceedings of eBRF 2004 in Tampere, Finland, 2004, pp. 267-281.

Porter, M.E. (2000), "Location, competition, and economic development: local clusters in a global economy”, Economic Development Quarterly, Vol. 14, No. 1, pp. 15-34.

Porter, M.E. (2001), "Clusters of innovation initiative: San Diego", available at: http://www.compete.org/publications/detail/218/clusters-of-innovation-initiative-san-diego/

Santos, F.M. and Eisenhardt, K.M. (2005), "Organizational boundaries and theories of organization”, Organization Science, Vol. 16, No. 5, pp. 491-508.

Suh, N.P. (2010), "A theory of innovation and case study", International Journal of Innovation Management, Vol. 14, No. 5, pp. 893-913.

Teece, D.J. (2007), "Explicating dynamic capabilities: the nature and microfoundations of (sustainable) enterprise performance", Strategic Management Journal, Vol. 28, No. 13, pp. 1319-1350.

Trott, P. (2012), Innovation Management and New Product Development, Pearson Education Limited, Harlow, UK.

Zwelling, L. and Kantarjian, H. M. (2014), “Obamacare: why should we care?”, Journal of Oncology Practice, Vol. 10, No. 1, pp. 12-14.

Walcott, S. M. (2002), "Analyzing an innovative environment: San Diego as a bioscience beachhead", Economic Development Quarterly, Vol. 16, No. 2, 99-114.

Walshok, M. and Shragge, A. (2014), Invention and Reinvention: The Evolution of San Diego's Innovation Economy, Stanford University Press, Stanford, California.

Walshok, M and West, J. (2014) "Serendipity and symbiosis: UCSD and the local wireless industry", in Kenney, M. and Mowery, D. (Eds.), Public Universities and Regional Growth: Insights from the University of California, Stanford University Press, pp. 127-152.

Whittington, K. B., Owen-Smith, J., and Powell, W. W. (2009), "Networks, propinquity, and innovation in knowledge-intensive industries", Administrative Science Quarterly, Vol. 54, No. 1, pp. 90-122.

Yin, R.K. (2009), Case study research: design and methods, $4^{\text {th }}$ ed, Sage Publications, Los Angeles.

Youtie, J. and Shapira, P. (2008), "Building an innovation hub: a case study of the transformation of university roles in regional technological and economic development", Research Policy, Vol. 37, No. 8, pp. 1188-1204. 
Appendix 1. PCT patent applications in the Greater Boston area, the San Francisco Bay area, and San Diego (OECD, 2014).

\begin{tabular}{|c|c|c|c|c|c|c|}
\hline & Region & 2006 & 2007 & 2008 & 2009 & 2010 \\
\hline \multirow{3}{*}{$\begin{array}{l}\text { PCT patent applications in } \\
\text { biotech (fractional count; } \\
\text { by inventor and priority } \\
\text { year) - count }\end{array}$} & $\begin{array}{l}\text { Boston-Worcester- } \\
\text { Manchester, MA-NH }\end{array}$ & 591.6 & 548.2 & 549.1 & 525.1 & 535.0 \\
\hline & $\begin{array}{l}\text { San Diego-Carlsbad- } \\
\text { San Marcos, CA }\end{array}$ & 299.1 & 278.7 & 268.5 & 287.8 & 270.2 \\
\hline & $\begin{array}{l}\text { San Jose-San Francisco- } \\
\text { Oakland, CA }\end{array}$ & 566.9 & 536.2 & 529.9 & 513.1 & 442.5 \\
\hline \multirow{3}{*}{$\begin{array}{l}\text { PCT patent applications in } \\
\text { the medical field (fractional } \\
\text { count; by inventor and } \\
\text { priority year) - count }\end{array}$} & $\begin{array}{l}\text { Boston-Worcester- } \\
\text { Manchester, MA-NH }\end{array}$ & 572.2 & 480.0 & 403.5 & 414.7 & 400.2 \\
\hline & $\begin{array}{l}\text { San Diego-Carlsbad- } \\
\text { San Marcos, CA }\end{array}$ & 154.3 & 143.7 & 153.7 & 136.9 & 165.6 \\
\hline & $\begin{array}{l}\text { San Jose-San Francisco- } \\
\text { Oakland, CA }\end{array}$ & 885.6 & 766.8 & 667.9 & 600.2 & 541.4 \\
\hline \multirow{3}{*}{$\begin{array}{l}\text { PCT patent applications in } \\
\text { pharmaceuticals (fractional } \\
\text { count; by inventor and } \\
\text { priority year) - count }\end{array}$} & $\begin{array}{l}\text { Boston-Worcester- } \\
\text { Manchester, MA-NH }\end{array}$ & 675.0 & 660.7 & 616.8 & 591.3 & 564.3 \\
\hline & $\begin{array}{l}\text { San Diego-Carlsbad- } \\
\text { San Marcos, CA }\end{array}$ & 398.2 & 381.4 & 345.0 & 304.0 & 288.3 \\
\hline & $\begin{array}{l}\text { San Jose-San Francisco- } \\
\text { Oakland, CA }\end{array}$ & 621.1 & 548.7 & 522.9 & 489.6 & 403.6 \\
\hline \multirow{3}{*}{$\begin{array}{l}\text { PCT patent applications in } \\
\text { biotech, the medical field, } \\
\text { and pharmaceuticals per } \\
\text { million inhabitants } \\
\text { (fractional count; by } \\
\text { inventor and priority year) - } \\
\text { level }\end{array}$} & $\begin{array}{l}\text { Boston-Worcester- } \\
\text { Manchester, MA-NH }\end{array}$ & 225.3 & 206.5 & 191.0 & 185.3 & 180.7 \\
\hline & $\begin{array}{l}\text { San Diego-Carlsbad- } \\
\text { San Marcos, CA }\end{array}$ & 288.9 & 270.1 & 253.9 & 238.1 & 233.1 \\
\hline & $\begin{array}{l}\text { San Jose-San Francisco- } \\
\text { Oakland, CA }\end{array}$ & 220.2 & 195.2 & 179.2 & 165.1 & 141.3 \\
\hline
\end{tabular}


Appendix 2. Indicators of the key actors in San Diego's health and life sciences ecosystem.

\begin{tabular}{|c|c|c|c|}
\hline Actor & $\begin{array}{r}\text { Revenue/budget/funding } \\
\text { (million USD/year) }\end{array}$ & Employees & Members \\
\hline UCSD & 3,600 & 28,700 & - \\
\hline The Salk Institute & 122 & 900 & - \\
\hline The Scripps Research Institute & 320 & 1,500 & - \\
\hline $\begin{array}{l}\text { Sanford-Burnham Medical } \\
\text { Research Institute }\end{array}$ & 152 & 850 & - \\
\hline Janssen Labs & - & - & 35 \\
\hline CONNECT & - & 12 & 320 \\
\hline BIOCOM & - & 28 & 600 \\
\hline $\begin{array}{l}\text { Wireless-Life Sciences } \\
\text { Alliance }\end{array}$ & - & 5 & 66 \\
\hline $\begin{array}{l}\text { San Diego Tech Coast Angels } \\
\text { (note: TCA total) }\end{array}$ & $\sim 5^{*}$ & - & 300 \\
\hline Qualcomm Life Fund & $\sim$ tens of* & - & - \\
\hline West-Health & $\sim$ tens of* & - & - \\
\hline Avalon Ventures & $\sim$ tens of* & - & - \\
\hline Domain & $\sim$ tens of* & - & - \\
\hline Illumina & 1,400 & $\begin{array}{r}1,500 \\
(3,100 * *)\end{array}$ & - \\
\hline Life Technologies $* * *$ & 3,800 & $\begin{array}{r}1,300 \\
(10,000 * *)\end{array}$ & - \\
\hline Qualcomm Life**** & 25,000 & $\begin{array}{r}10,000 \\
(26,000 * *)\end{array}$ & - \\
\hline Sharp Healthcare & 2,700 & 14,000 & - \\
\hline Scripps Health & 2,500 & 15,000 & - \\
\hline UC San Diego Health System & $1,000^{*}$ & 7,500 & - \\
\hline Kaiser Permanente & $2,500^{*}$ & $10,000 *$ & - \\
\hline
\end{tabular}

